\title{
A comparison between metatarsal head-resurfacing hemiarthroplasty and total metatarsophalangeal joint arthroplasty as surgical treatments for hallux rigidus: a retrospective study with short- to midterm follow-up
}

This article was published in the following Dove Press journal:

Clinical Interventions in Aging

13 December 2016

Number of times this article has been viewed

\author{
Musa Ugur Mermerkaya' \\ Houman Adli ${ }^{2}$ \\ 'Department of Orthopaedics and \\ Traumatology, Medical School, \\ Bozok University, ${ }^{2}$ Department of \\ Orthopaedics and Traumatology, \\ Yozgat State Hospital, Yozgat, Turkey
}

Purpose: We evaluated the short- to midterm outcomes of metatarsal head-resurfacing hemiarthroplasty and total metatarsophalangeal joint arthroplasty (total joint replacement [TJR]) as surgical treatments for advanced-stage hallux rigidus (HR).

Patients and methods: From 2012 to 2014, all data from patients who underwent surgery for the treatment of grades 2-3 HR were retrospectively reviewed, and 45 patients were included in this study. Of these patients, 26 underwent metatarsal head-resurfacing hemiarthroplasty (Group I) and 19 underwent TJR (Group II). All patients were clinically graded prior to surgery and at their final follow-up visits using the American Orthopedic Foot and Ankle Society's (AOFAS) hallux metatarsophalangeal-interphalangeal scale, a visual analog scale (VAS), and the "first metatarsophalangeal joint range of motion" (MTPJ ROM) score.

Results: Metatarsal head resurfacing was performed on 26 patients. Two patients underwent bilateral procedures, yielding a total of 28 cases in Group I. TJR was performed on 19 patients in Group II. Of the 26 Group I patients, 12 (46.2\%) were male and 14 (53.8\%) were female, with a mean age of $56.3 \pm 4.5$ years (range: $47-63$ years); the mean follow-up duration was $29.9 \pm 5.2$ months. Of the 19 Group II patients, eight (42.1\%) were male and eleven $(57.9 \%)$ were female, with a mean age of 57.1 \pm 5.8 years (range: $45-66$ years); the mean follow-up duration was 27.1 \pm 7.5 months. Significant improvements were evident in the AOFAS scores, and the VAS scores decreased, in both groups. No significant difference was evident between groups I and II.

Conclusion: After failure of conservative treatment in patients with moderate-to-severe HR, both MTPJ hemiarthroplasty and TJR were associated with effective recovery of toe function and MTPJ ROM, as well as good short- to midterm functional outcomes.

Keywords: hallux rigidus, arthroplasty, surgical treatment, HemiCAP ${ }^{\circledR}$, ToeFit-Plus ${ }^{\circledR}$

\section{Introduction}

Hallux rigidus (HR) is a common degenerative foot disease characterized by pain and a decreased range of motion (ROM) of the first metatarsophalangeal joint (MTPJ). ${ }^{1}$ HR can be either idiopathic or traumatic (micro- or macrotrauma to the cartilage of the first MTPJ can damage, and trigger erosion of, joint surfaces) and is associated with the production of dorsal osteophytes. ${ }^{2-7}$ Several conservative and surgical treatment options have been reported in the literature; age, activity level, patient expectations,
Correspondence: Musa Ugur Mermerkaya Department of Orthopaedics and Traumatology, Medical School, Bozok University, Yozgat 66200, Turkey Tel +905323346696

Email drugurmermerkaya@gmail.com 
and the severity of arthrosis must be considered when choosing the best treatment option. ${ }^{2-20}$ However, the management of advanced HR (stages II and III) remains controversial; many authors have reported a variety of techniques, including interposition arthroplasty, resection arthroplasty, partial or total MTPJ arthroplasty, and joint fusion. ${ }^{8,10-18}$ Although MTP arthrodesis has been advocated by many surgeons, implant arthroplasty also appears to be successful when used to treat advanced HR. ${ }^{8,21}$

Implant arthroplasty of the MTPJ has been used by orthopedic surgeons for the past 60 years; various arthroplasty implants have been placed in an attempt to restore the function of the first MTP joint. ${ }^{5,22-26}$ However, the early implants were disappointing, and the failure rates were high. Subsequent silastic designs were plagued by either implant fracture or permanent deformation. ${ }^{9,27,28}$ Over the years, the performance and the durability of implants have improved, attributable to advances in design and metallurgy; implant placement is now a viable alternative treatment for HR.

The ToeFit-Plus ${ }^{\circledR}$ implant (Smith and Nephew, London, $\mathrm{UK}$ ) is a fourth-generation prosthesis, designed with a particular focus on the biomechanical requirements of the first MTPJ and benefiting from experience with earlier implants. The prosthesis is composed of a tapered, threaded, conical titanium core, which avoids any need for cement. On the metatarsal side, a cobalt chrome metatarsal head is tapped into the titanium core and to accommodate the proximal phalanx, a polyethylene phalangeal plate is clipped to the core.

The HemiCAP ${ }^{\circledR}$ Toe Classic system (Arthrosurface Inc, Franklin, MA, USA) was introduced in 2005 and the design was guided by the anatomy and kinematics of the first MTPJ. ${ }^{29}$ The implant can be used to resurface damaged articular surfaces and restore the unique joint geometry of each patient, with minimal bone resection. Degenerative cartilage at the metatarsal head is removed, and the partial joint-simulating implant is then placed.

Recently, total MTPJ arthroplasty (total joint replacement [TJR]) and metatarsal-resurfacing hemiarthroplasty have been commonly used to treat HR. The aim of this study was to compare the functional outcomes after, and short- to midterm results of, metatarsal head-resurfacing hemiarthroplasty and total MTPJ arthroplasty used to treat patients with advanced HR.

\section{Patients and methods}

This study was approved by the Ethics Committee of Bozok University. Written informed consent was obtained from all patients to be included in the study. The patients have provided written informed consent for their x-rays to be used in this publication. Between 2012 and 2014, 50 patients who underwent surgery to treat grades 2-3 HR were retrospectively reviewed. Five patients were excluded from the study. The exclusion criteria were any previous surgical procedure on the same foot ( $\mathrm{n}=1$ patient), an increased intermetatarsal angle $\left(>10^{\circ}\right)$ or hallux valgus angle $\left(>15^{\circ}\right)(\mathrm{n}=2$ patients $)$, joint infection, neuropathy ( $n=1$ patient), osteomyelitis, erosive systemic arthritis, inadequate bone stock, nickel allergy, inflammatory arthritis ( $\mathrm{n}=1$ patient), and/or postinfectious arthritis. Forty-five patients were ultimately included in the study. Of these patients, 26 underwent metatarsal head-resurfacing hemiarthroplasty (Group I) and 19 underwent TJR (Group II). The nature of the surgical intervention was explained to each patient, all of whom provided written informed consent. The two authors performed all surgical procedures in two centers. The primary outcome measures were changes in American Orthopedic Foot and Ankle Society's (AOFAS) hallux metatarsophalangeal-interphalangeal, MTPJ ROM, and visual analog scale (VAS) scores. Data were collected at the time of initial admission and at the final follow-up visit. ${ }^{30,31}$

All patients were clinically assessed by the two authors prior to surgery; AOFAS scores, MTPJ ROMs, and VAS scores were determined. ${ }^{17,18}$ Patients were graded using the Hattrup and Johnson radiographic system, ${ }^{5}$ which was developed to radiographically evaluate HR with reference to increasing osteophyte production, narrowing of the joint space, and the extent of subchondral sclerosis. ${ }^{5}$ Only patients with grade 2 (moderate osteophyte numbers with narrowing of joint space and subchondral sclerosis) or grade 3 HR (marked levels of osteophytes, loss of joint space, and possible subchondral cysts) evident upon preoperative radiographic review were considered for inclusion. Standardized weight-bearing anteroposterior and lateral radiographs of the foot were obtained prior to surgery and as part of the clinical follow-up. We assessed joint space, periprosthetic radiolucency (in millimeters), any implant disassembly, implant subsidence (in millimeters), any recurrence of dorsal osteophytes, interphalangeal arthritis, elevation of the first ray, and the declination angle of the first metatarsal (normal range: $\left.19^{\circ}-25^{\circ}\right) .{ }^{32-34}$ The final follow-up evaluation included repeat determinations of the AOFAS score and MTPJ ROM. Standard weight-bearing anteroposterior and lateral foot radiographs were used to evaluate any changes in implant position, or loosening, during the follow-up period. All complications observed during follow-up were recorded by the same observers. 


\section{Operative technique}

All surgical procedures were performed under regional anesthesia after a tourniquet had been tied to the calf; prophylactic antibiotic therapy (a first-generation cephalosporin; $2 \mathrm{mg} / \mathrm{kg}$ ) was also given. The joint was accessed via a dorsal/medial approach and the long extensor tendon of the hallux was laterally retracted. The first MTPJ capsule was opened longitudinally and the first metatarsal head exposed by plantar flexion of the toe. Adhesions around the sesamoidal region and the MTPJ were released until sufficient $\left(\geq 90^{\circ}\right)$ dorsiflexion of the MTPJ was achieved relative to the plantar surface.

We performed metatarsal head-resurfacing hemiarthroplasty (Group I) with implantation (without cement) of an appropriately sized HemiCAP ${ }^{\circledR}$ Toe Classic (Arthrosurface Inc) resurfacing implant that was slightly impacted (Figures 1 and 2). In the TJR group (Group II), we implanted a ToeFit-Plus ${ }^{\circledR}$ (Smith and Nephew) into the metatarsal and phalangeal bed (Figures 3 and 4). We checked the ROM

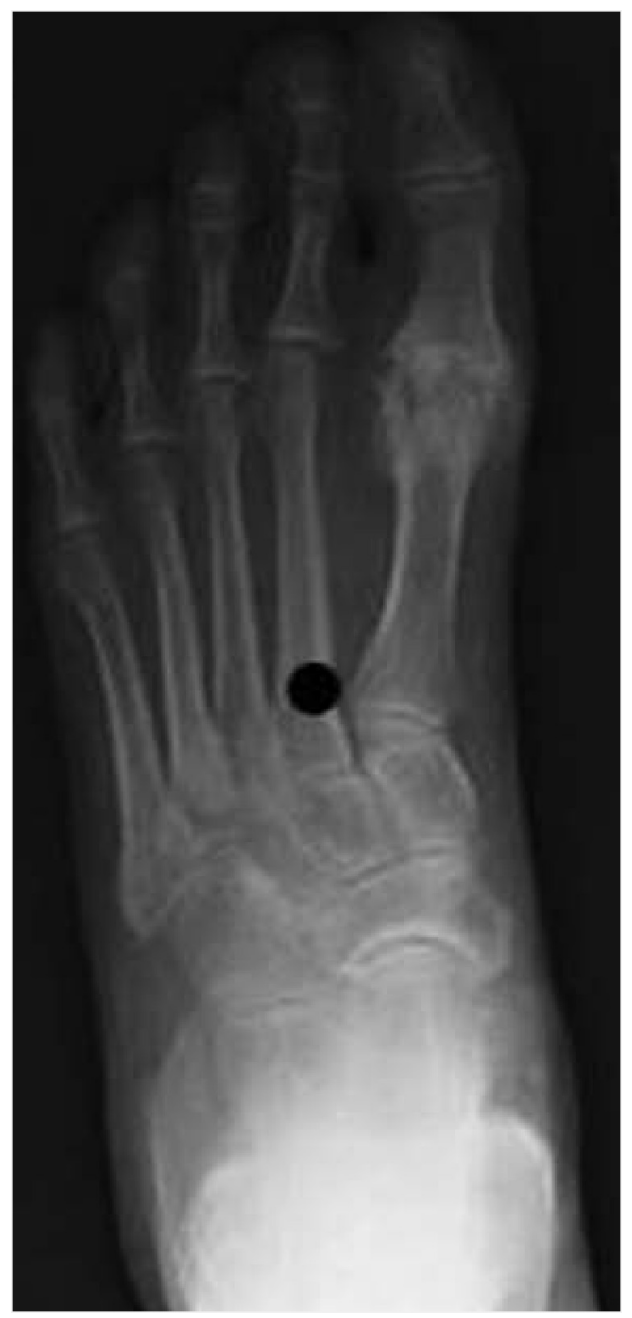

Figure I Preoperative anteroposterior view of patient's metatarsals.

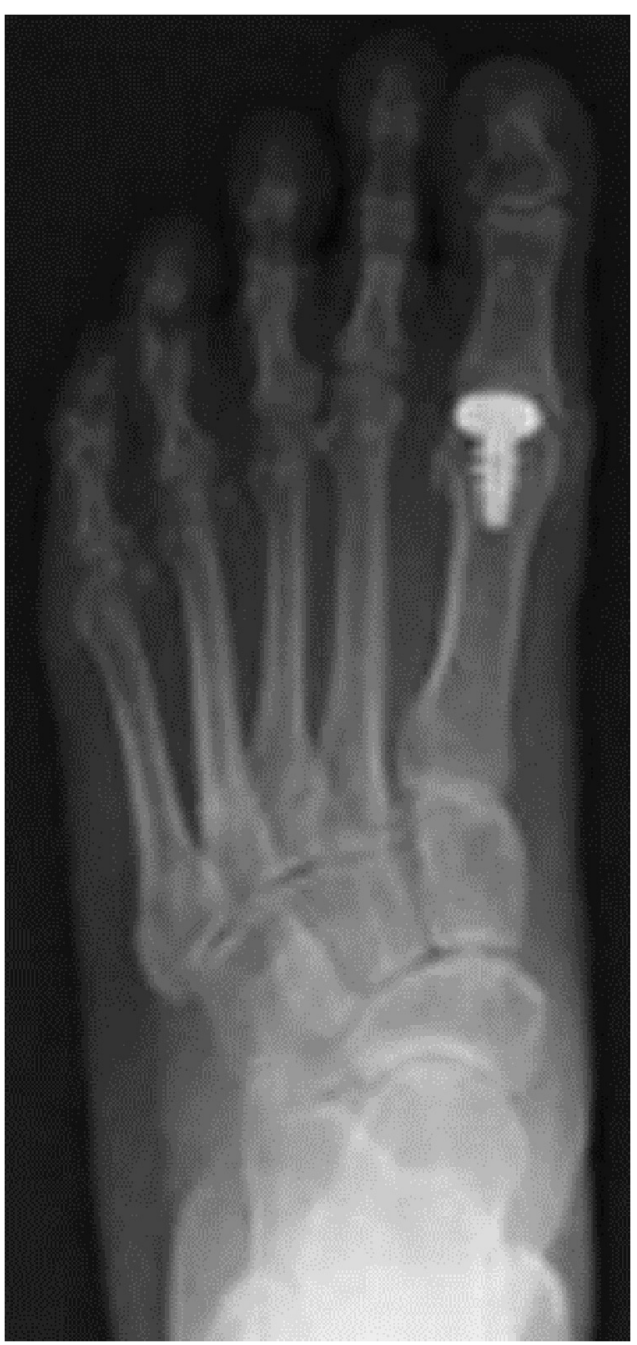

Figure 2 Postoperative anteroposterior views of metatarsals of a patient in the metatarsal-resurfacing group.

of the MTPJ to detect any impingement, loose body, or periarticular adhesion. We repaired the joint capsule after releasing the tourniquet. An elastic bandage was applied after closing the wound; no patient required a drain.

\section{Postoperative rehabilitation}

The postoperative protocol was identical for all patients. The operated limb was elevated and an ice pad was applied to the wound. Anteroposterior and lateral radiographs were obtained in the immediate postoperative period. Passive ROM exercises were initiated within the first postoperative day, and active ROM exercises commenced after removal of the skin sutures on the 15th postoperative day. Patients began full weight-bearing exercises at the end of the first postoperative month. Patients were evaluated at the following postoperative time points: 1 month, 3 months, 6 months, and 12 months, and during their later final follow-up visits. 


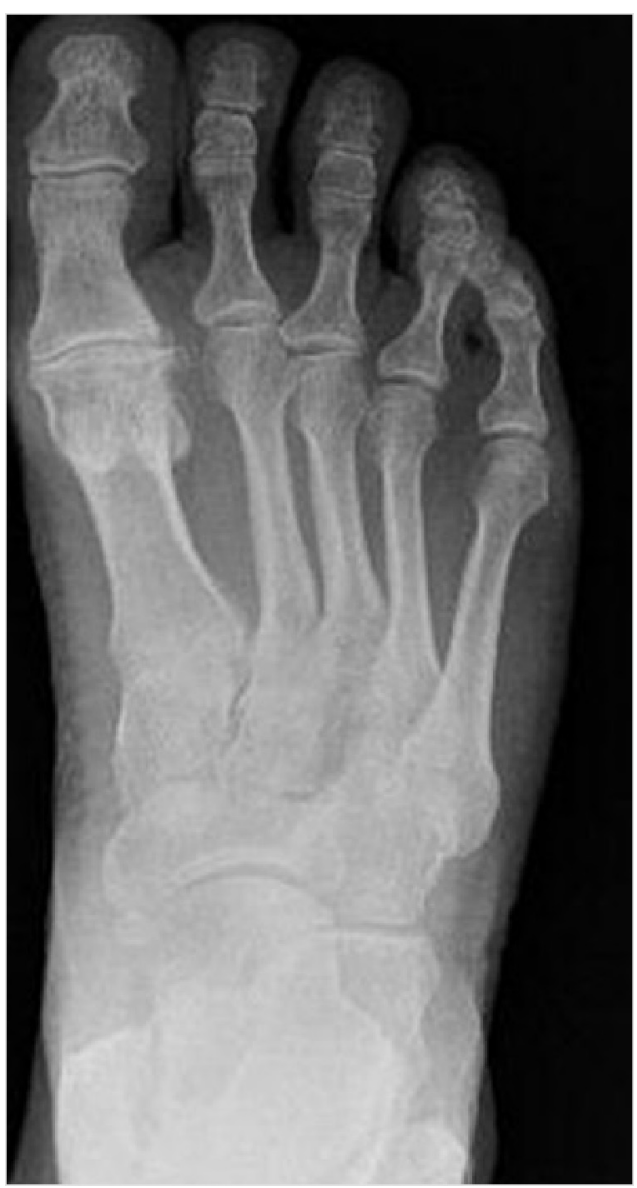

Figure 3 Preoperative anteroposterior view of patient's metatarsals.

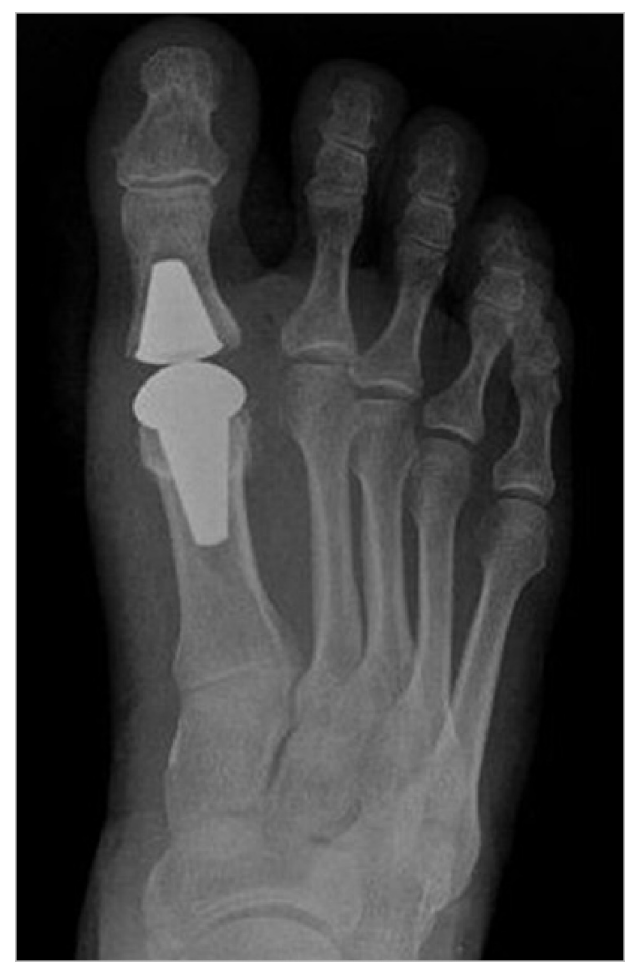

Figure 4 Postoperative anteroposterior views of the metatarsals of a patient in the total joint replacement group.

\section{Statistical analysis}

Data analysis was performed using SPSS for Windows software (version 17.0; SPSS Inc, Chicago, IL, USA). We explored the distributions of continuous variables using the Kolmogorov-Smirnov test. The Levene test was used to evaluate the homogeneity of variance. Data are given as mean \pm standard deviation, or as median (minimummaximum), for continuous variables. Categorical data are shown as number of cases with percentage. The mean differences between groups were compared using Student's $t$-test. When two independent groups were compared, the Mann-Whitney $U$-test was used to compare medians; otherwise, the Kruskal-Wallis test was applied. Categorical data were analyzed using the chi-squared or Fisher's exact test, as appropriate. We used the Wilcoxon Sign-Rank test to explore whether differences between pre- and postoperative clinical measurements were significant. Associations between continuous variables were evaluated by Spearman rank correlation analysis. A $P$-value $<0.05$ was considered to reflect statistical significance. When we performed multiple comparisons, the Bonferroni correction was applied to control for type I error.

\section{Results}

Metatarsal head resurfacing was performed on 26 patients. Two patients underwent bilateral procedures, yielding a total of 28 cases in Group I. TJR was performed on 19 patients in Group II. Of the 26 patients of Group I, $12(46.2 \%)$ were male and $14(53.8 \%)$ were female, with a mean age of $56.3 \pm 4.5$ years (range: $47-63$ years). Of the 19 Group II patients, eight (42.1\%) were male and eleven $(57.9 \%)$ were female, with a mean age of $57.1 \pm 5.8$ years (range: 45-66 years) (Table 1).

Table I Baseline characteristics of cases in the two groups

\begin{tabular}{|c|c|c|c|}
\hline Variable & $\begin{array}{l}\text { Group I } \\
(n=26)\end{array}$ & $\begin{array}{l}\text { Group II } \\
(n=19)\end{array}$ & P-value \\
\hline Age, years (mean $\pm S D)$ & $56.3 \pm 4.5$ & $57.1 \pm 5.8$ & $0.630^{\mathrm{a}}$ \\
\hline Sex, n (\%) & & & $0.787^{b}$ \\
\hline Male & 12 (46.2\%) & $8(42.1 \%)$ & \\
\hline Female & | 4 (53.8\%) & I| (57.9\%) & \\
\hline \multicolumn{4}{|l|}{ Side, n (\%) } \\
\hline Left & $12(46.2 \%)$ & I I (57.9\%) & $0.436^{b}$ \\
\hline Right & $12(46.2 \%)$ & $8(42.1 \%)$ & $0.787^{b}$ \\
\hline Bilateral & $2(7.6 \%)$ & 0 & $0.50 \mathrm{I}^{\mathrm{c}}$ \\
\hline Grade, n (\%) & & & $0.878^{b}$ \\
\hline 2 & $9(34.6 \%)$ & $7(36.8 \%)$ & \\
\hline 3 & 17 (65.4\%) & $12(63.2 \%)$ & \\
\hline $\begin{array}{l}\text { Follow-up time, months } \\
\text { (mean } \pm \mathrm{SD} \text { ) }\end{array}$ & $29.9 \pm 5.2$ & $27.1 \pm 7.5$ & $0.138^{a}$ \\
\hline
\end{tabular}

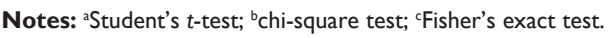
Abbreviation: SD, standard deviation. 
Table 2 Pre- and postoperative clinical measurements

\begin{tabular}{|c|c|c|c|c|c|}
\hline Variable & Preoperative & Postoperative & $P$-value ${ }^{a}$ & Difference & $P$-value ${ }^{b}$ \\
\hline ROM score & & & & & 0.632 \\
\hline Group I & $27.5(15-40)$ & $75(35-85)$ & $<0.001$ & $47.5(10-65)$ & \\
\hline Group II & $25(15-35)$ & $75(70-85)$ & $<0.001$ & $50(40-65)$ & \\
\hline AOFAS score & & & & & 0.765 \\
\hline Group I & $33(22-48)$ & 87.7 (72-96) & $<0.001$ & $54(38-74)$ & \\
\hline Group II & $31(22-47)$ & $83(77-96)$ & $<0.001$ & $54(32-67)$ & \\
\hline VAS score & & & & & 0.549 \\
\hline Group I & $8.5(7-10)$ & $2(I-3)$ & $<0.001$ & $-6.5(-9$ to -4$)$ & \\
\hline Group II & $9(7-10)$ & $2(I-3)$ & $<0.001$ & $-7(-9$ to -4$)$ & \\
\hline
\end{tabular}

Notes: Data in bold indicates statistical significance. Data presented as ROM score (range) (degrees), AOFAS score (range), VAS score (range), unless stated otherwise. ${ }^{\mathrm{a}}$ The comparisons between pre- and postoperative clinical measurements within groups: Wilcoxon Sign-Rank test, according to the Bonferroni correction; $P<0.025$ was considered statistically significant; ${ }^{b}$ comparisons among groups in terms of differences in clinical measurements: Mann-Whitney $U$-test; $P<0.05$ was considered statistically significant. Abbreviations: AOFAS, American Orthopedic Foot and Ankle Society; ROM, range of motion; VAS, visual analog scale.

Upon preoperative radiographic staging using the Hattrup and Johnson classification, $65.4 \%$ of all Group I cases had grade $3 \mathrm{HR}$ and $34.6 \%$ had grade $2 \mathrm{HR}$. In Group II, $63.2 \%$ of all cases had grade $3 \mathrm{HR}$ and $36.8 \%$ had grade $2 \mathrm{HR}$. The mean follow-up durations were 29.9 \pm 5.2 months for Group I and 27.1 \pm 7.5 months for Group II. Baseline characteristics are shown in Table 1. The groups did not differ significantly in terms of age, sex, operative side, disease grade, or follow-up time (all $P>0.05$ ) (Table 1).

In Group I, the mean preoperative first MTPJ ROM was $27.5^{\circ}$ (range: $15^{\circ}-40^{\circ}$ ), which had increased to $75^{\circ}$ (range: $\left.35^{\circ}-85^{\circ}\right)$ at the final follow-up visit $(P<0.001)$. In Group II, the mean preoperative first MTPJ ROM was $25^{\circ}$ (range: $15^{\circ}-35^{\circ}$ ), which had increased to $75^{\circ}$ (range: $70^{\circ}-85^{\circ}$ ) at the final follow-up visit $(P<0.001)$ (Table 2).

Significant increases in postoperative ROM were evident in both groups $(P<0.001)$. The delta ROMs of the two groups did not differ significantly $(P=0.632$ ) (Table 2$)$. Both groups exhibited significant increases in the AOFAS scores $(P<0.001)$. The delta AOFAS scores of the two groups did not differ significantly $(P=0.765)$ (Table 2$)$. Both groups exhibited significant decreases in VAS scores $(P<0.001)$. The delta VASs of the two groups did not differ significantly ( $P=0.549$ ) (Table 2).

Sex did not influence the postoperative improvements in ROM, AOFAS, or VAS scores $(P=0.676, P=0.963$, and $P=0.712$, respectively). The operative side did not influence the postoperative improvements in ROM, AOFAS, or VAS scores ( $P=0.771, P=0.768$, and $P=0.248$, respectively). The disease grade did not influence the postoperative improvements in ROM, AOFAS, or VAS scores $(P=0.399, P=0.476$, and $P=0.408$, respectively) (Table 3 ).

Age did not affect the improvement in ROM ( $r=-0.006$, $P=0.969)$, AOFAS score $(r=0.146, P=0.339)$, or VAS score $(r=0.222, P=0.143)$. No significant correlation was evident between the difference in the ROM and the AOFAS score ( $r=0.125, P=0.415)$. No significant correlation was evident between the difference in the ROM and the VAS score ( $r=0.179, P=0.239$ ). No significant correlation was evident between the difference in AOFAS and VAS scores $(r=0.046$, $P=0.765$ ) (Table 4).

No patient exhibited any sign of implant loosening, subsidence, or disengagement; no periprosthetic radiolucency suggestive of implant wear was noted. One superficial wound infection developed in the early postoperative period in a patient in Group I, which delayed wound healing. Cultures were negative and the wound was treated by frequent changes of dressings over a period of 3 weeks. All wounds eventually healed completely.

\section{Discussion}

HR is common, affecting up to $10 \%$ of all adults. ${ }^{19}$ It can cause debilitating pain and functional limitations during

Table 3 Differences in clinical measurements in terms of groups' baseline characteristics

\begin{tabular}{|c|c|c|c|}
\hline Variables & $\Delta R O M$ & $\triangle$ AOFAS & $\Delta$ VAS \\
\hline \multicolumn{4}{|l|}{ Sex } \\
\hline Male & $50(10-65)$ & $53.5(32-67)$ & $-7(-9$ to -4$)$ \\
\hline Female & $45(35-65)$ & 54 (39-74) & $-7(-9$ to -4$)$ \\
\hline$P$-value ${ }^{a}$ & 0.676 & 0.963 & 0.712 \\
\hline \multicolumn{4}{|l|}{ Side } \\
\hline Left & $50(10-65)$ & $53(32-67)$ & $-6(-8$ to -4$)$ \\
\hline Right & $47.5(40-65)$ & $53.5(38-74)$ & $-7(-9$ to -4$)$ \\
\hline Bilateral & $51.2(45-57.5)$ & $56.5(55.5-57.5)$ & $-6.5(-8$ to -5$)$ \\
\hline$P$-value ${ }^{b}$ & 0.771 & 0.768 & 0.248 \\
\hline \multicolumn{4}{|l|}{ Grade } \\
\hline 2 & $45(35-60)$ & $51.5(39-67)$ & $-7(-8$ to -4$)$ \\
\hline 3 & $50(10-65)$ & $55(32-74)$ & $-7(-9$ to -4$)$ \\
\hline$P$-value ${ }^{\mathrm{a}}$ & 0.399 & 0.476 & 0.408 \\
\hline
\end{tabular}

Notes: Data presented as ROM score (range) (degrees), AOFAS score (range), VAS score (range), unless stated otherwise. ${ }^{a}$ Mann-Whitney U-test; ' ${ }^{6} K$ ruskal-Wallis test. Abbreviations: AOFAS, American Orthopedic Foot and Ankle Society; ROM, range of motion; VAS, visual analog scale. 
Table 4 The results of correlation analyses

\begin{tabular}{lll}
\hline Analysis & Correlation coefficient & $\boldsymbol{P}_{\text {-value }}$ \\
\hline Age vs $\triangle$ ROM & -0.006 & 0.969 \\
Age vs $\triangle$ AOFAS & 0.146 & 0.339 \\
Age vs $\triangle$ VAS & 0.222 & 0.143 \\
$\Delta$ ROM vs $\triangle$ AOFAS & 0.125 & 0.415 \\
$\triangle$ ROM vs $\triangle$ VAS & 0.179 & 0.239 \\
$\triangle$ AOFAS vs $\triangle$ VAS & 0.046 & 0.765 \\
\hline
\end{tabular}

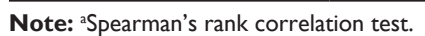

Abbreviations: AOFAS, American Orthopedic Foot and Ankle Society; ROM, range of motion; VAS, visual analog scale.

both low- and high-impact activities of daily living. Patients with advanced-stage HR are typically aged 50-60 years and require maintenance of MTPJ motion. Therefore, treatment goals are dictated by disease stage, patient expectations, and procedural suitability in terms of both immediate and long-term requirements. The primary patient expectations are usually pain relief and functional improvement. Oral nonsteroidal anti-inflammatory drugs, activity restrictions, footwear modifications, and intra-articular steroid injections are the principal conservative treatment options for early management of HR. ${ }^{20}$ However, management of advanced (stages II and III) HR remains controversial; many authors have described various methods, including interposition arthroplasty, resection arthroplasty, partial or total MTPJ arthroplasty, and joint fusion. ${ }^{8-18}$ Arthrodesis has been advocated by many authors as a useful treatment for advanced HR, and a recent study has described the outcomes of this technique after 30 months of follow-up. ${ }^{34-37}$ However, arthrodesis has limitations in terms of patients who desire ROM and are uncomfortable with the idea of a fusion. Metallic hemiarthroplasties that resurface the phalangeal base have been shown to not be associated with malrotation, malpositioning, malunion, or nonunion 79.4 months later, rendering the latter procedure more attractive to active patients. ${ }^{36-39}$ Loss of first-MTPJ motion may not be acceptable to active patients who plan to resume daily activities. Many patients demand a mobile and pain-free MTPJ. ${ }^{15}$

The ToeFit-Plus ${ }^{\circledR}$ joint replacement (Smith and Nephew), a fourth-generation prosthesis designed with a particular focus on the biomechanical requirements of the first MTPJ, benefits from experience with previous implants. The prosthesis is composed of a tapered, threaded, conical titanium core, avoiding any need for cement. On the metatarsal side, a cobalt chrome metatarsal head is tapped into the titanium core and, to accommodate the proximal phalanx, a polyethylene phalangeal plate is clipped to the titanium core.
Metatarsal head resurfacing with the HemiCAP ${ }^{\circledR}$ system also uses a fourth-generation implant; the technique involves replacement of the damaged articular surface with a patientspecific implant and requires minimal removal of cartilage and bone. The technique thus allows preservation of normal metatarsal bone and cartilage, which facilitates salvage procedures if revision surgery is required. Other benefits include maintenance of intrinsic muscle function, no change to the contours of joint surfaces, the ability to decompress the MTPJ (if necessary), and stable screw fixation. ${ }^{4}$

Our total MTPJ arthroplasty patients with new metalon-polyethylene articulations enjoyed good clinical and radiographic outcomes at a minimum of 2 years of follow-up. The mean postoperative AOFAS-hallux metatarsophalangeal interphalangeal score of 83 was similar to those attained after MTP arthroplasty. ${ }^{25,40-43}$

Daniilidis et $\mathrm{al}^{44}$ reported an increase in the average AOFAS score from 44 preoperatively to 82.5 at 18 months postoperatively. Preoperative average VAS pain scores in the cited study also improved, from 7.0 preoperatively to 2.0 at the final follow-up; however, radiolucent lines were noted in $13 \%$ of patients. ${ }^{44}$ Barták et $\mathrm{al}^{45}$ retrospectively studied 28 patients who had undergone either hemiarthroplasty or total joint arthroplasty. At 2 years' follow-up, radiographic asymptomatic osteolysis was evident in three patients; three required revisions to treat mobility restrictions and pain; but, overall, both the functional and pain scores improved. In a prospective study, Lange et $\mathrm{al}^{43}$ found that, despite functional improvement, $28.7 \%$ of 78 patients exhibited osteolysis and $10 \%$ required revisions at a mean follow-up time of 56 months.

The functional and pain scores of our patients are consistent with those of previous studies. However, we found no evidence of radiolucency, implant loosening, subsidence, or disengagement at a mean follow-up time of 27 months.

Carpenter et $\mathrm{al}^{4}$ reported good functional results in 32 patients over a mean follow-up period of 27.3 months after metatarsal head resurfacing and no patient required revision. Hasselman and Shields ${ }^{12}$ reported only two failures in $>100$ patients with high-grade HR treated with $\mathrm{HemiCAP}^{\circledR}$ prostheses; the mean follow-up period was 30 months. Patient satisfaction rates were high and the functional outcomes good in all 25 included patients over a mean follow-up period of 20 months. Aslan et $\mathrm{al}^{2}$ reported the early outcomes of HemiCAP $^{\circledR}$ resurfacing hemiarthroplasty of 27 toes; the mean AOFAS score improved (from 40.94 to 85.1), as did the first MTPJ ROM (from $14.36^{\circ}$ to $54.38^{\circ}$ ), with no instance of failure. Erdil et $\mathrm{al}^{46}$ performed metatarsal head-resurfacing hemiarthroplasty on 14 feet and reported that the mean 
Table 5 Summary of previously published studies reporting clinical results of the surgical treatment of hallux rigidus

\begin{tabular}{|c|c|c|c|c|c|c|c|c|}
\hline Study & Operation & Procedures & $\begin{array}{l}\text { Mean age } \\
\text { (years) }\end{array}$ & $\begin{array}{l}\text { Mean } \\
\text { follow-up } \\
\text { (months) }\end{array}$ & $\begin{array}{l}\text { Mean } \\
\text { AOFAS } \\
\text { score }\end{array}$ & Complication & $\begin{array}{l}\text { Mean } \\
\text { DROM } \\
\text { (degrees) }\end{array}$ & $\begin{array}{l}\text { Mean VAS pain } \\
\text { score; AOFAS } \\
\text { pain subscore } \\
\end{array}$ \\
\hline Fuhrmann et $\mathrm{a}^{4 \mid}$ & $\begin{array}{l}\text { Total MTP } \\
\text { arthroplasty }\end{array}$ & 43 & $\mathrm{~N} / \mathrm{A}$ & $25-28$ & 90.0 & $\begin{array}{l}9 \% \text {, four conversions } \\
\text { to fusion }\end{array}$ & 45 & AOFAS: $32.8 / 40$ \\
\hline $\begin{array}{l}\text { Gibson and } \\
\text { Thomson }^{8}\end{array}$ & $\begin{array}{l}\text { Total MTP } \\
\text { arthroplasty }\end{array}$ & 39 & 55.5 & 24.0 & $\mathrm{~N} / \mathrm{A}$ & $\begin{array}{l}\text { I5\%, six phalangeal } \\
\text { component loosening } \\
\text { and revision }\end{array}$ & 24.0 & VAS: 2.7 \\
\hline Barták et $\mathrm{al}^{45}$ & $\begin{array}{l}\text { Total MTP } \\
\text { arthroplasty }\end{array}$ & 28 & 56.3 & 24 & $\mathrm{~N} / \mathrm{A}$ & $\begin{array}{l}\text { Asymptomatic } \\
\text { osteolysis (three } \\
\text { patients) }\end{array}$ & $\mathrm{N} / \mathrm{A}$ & $\mathrm{N} / \mathrm{A}$ \\
\hline Daniilidis et $\mathrm{al}^{44}$ & $\begin{array}{l}\text { Total MTP } \\
\text { arthroplasty }\end{array}$ & 23 & 57 & 18 & 82.5 & $\begin{array}{l}\text { Radiolucency (three } \\
\text { patients) }\end{array}$ & 52.5 & VAS: 1.7 \\
\hline $\begin{array}{l}\text { Hasselman and } \\
\text { Shields }{ }^{12}\end{array}$ & $\begin{array}{l}\text { Metatarsal head } \\
\text { resurfacing }\end{array}$ & 25 & 51 & 20 & 96.1 & $\begin{array}{l}\text { Metallosis and } \\
\text { infection in one } \\
\text { patient each }\end{array}$ & 65 & $\mathrm{~N} / \mathrm{A}$ \\
\hline Carpenter et $\mathrm{al}^{4}$ & $\begin{array}{l}\text { Metatarsal head } \\
\text { resurfacing }\end{array}$ & 32 & 62.8 & 27.3 & 89.3 & None & 89.3 & AOFAS: $36.5 / 40$ \\
\hline Aslan et $\mathrm{al}^{2}$ & $\begin{array}{l}\text { Metatarsal head } \\
\text { resurfacing }\end{array}$ & 27 & 58 & 37.6 & 85.1 & None & 54.3 & VAS: 2.05 \\
\hline Meric et $\mathrm{a}{ }^{47}$ & $\begin{array}{l}\text { Metatarsal head } \\
\text { resurfacing }\end{array}$ & 14 & 58.7 & 24.1 & 83.7 & $\begin{array}{l}\text { One revision to } \\
\text { arthrodesis }\end{array}$ & 69.6 & VAS: I.2 \\
\hline $\begin{array}{l}\text { Kline and } \\
\text { Hasselman }{ }^{48}\end{array}$ & $\begin{array}{l}\text { Metatarsal head } \\
\text { resurfacing }\end{array}$ & 30 & 51 & 60.0 & 94.1 & $\begin{array}{l}\text { I3\%, three silastic } \\
\text { implants at } 3 \text { years, } \\
\text { one arthrodesis }\end{array}$ & 66.3 & AOFAS: $32 / 40$ \\
\hline
\end{tabular}

Note: Pain was reported either as VAS pain score $(0=$ no pain, $10=$ worst pain $)$ or AOFAS pain subscore $(0=$ severe/almost always present, $40=$ no pain).

Abbreviations: AOFAS, American Orthopedic Foot and Ankle Society; DROM, dorsiflexion range of motion; MTP, metatarsophalangeal; N/A, not applicable; VAS, visual analog scale.

first-MTPJ ROM improved significantly from a preoperative value of $22.2^{\circ} \pm 5.6^{\circ}$ (range: $10^{\circ}-28^{\circ}$ ) to a postoperative value of $56.3^{\circ} \pm 9.6^{\circ}$ (range: $40^{\circ}-65^{\circ}$ ). Meriç et $\mathrm{al}^{47}$ reported the early outcomes of metatarsal head-resurfacing hemiarthroplasty on 14 feet; the mean AOFAS score improved (from 33.5 \pm 9.8 to $83.7 \pm 10.1$ ), as did the first MTPJ ROM (from $22.8^{\circ}$ to $69.6^{\circ}$ ), with one failure. Kline and Hasselman ${ }^{48}$ reported the longerterm outcomes of patients receiving a fourth-generation MTPresurfacing implant; the device was durable and afforded excellent pain relief and functional improvement at an average follow-up time of 5 years. Our results are consistent with those of previous studies. Table 5 summarizes the clinical outcomes of previous studies on surgical treatment of HR.

We observed significant improvements in AOFAS scores, and significant decreases in VAS scores, in both groups during shortterm follow-up. No significant between-group difference was evident at the last follow-up. We found no radiolucency, and no evidence of implant loosening, subsidence, or disengagement at mean follow-up times of 29.9 months in Group I and 27.1 months in Group II.

Our study was limited by its observational and retrospective design and relatively small patient numbers.
Another limitation was that all procedures were performed by two surgeons, using a standardized technique, in two centers. Furthermore, we did not assess patient satisfaction (eg, by using the Medical Health Outcomes Short-Form 36-item survey instrument). Ideally, a prospective, multicenter randomized trial is required. Comparative studies of the long-term outcomes of various surgical techniques, with larger case series of similar patients, are required.

\section{Conclusion}

If conservative treatment fails in patients with moderateto-severe HR, first-MTPJ hemiarthroplasty and TJR effectively permit recovery of toe function and first-MTPJ $\mathrm{ROM}$, in addition to affording good short- to midterm functional outcomes.

\section{Acknowledgment}

The authors received no financial support for the research, authorship, and/or publication of this article.

\section{Disclosure}

The authors report no conflicts of interest in this work. 


\section{References}

1. Bankes MJK, Shah RR, Grace DL. Swanson double-stem arthroplasty of the hallux: a survivorship analysis. Foot Ankle Surg. 1999;5: 235-243.

2. Aslan H, Citak M, Bas EG, Duman E, Aydin E, Ates Y. Early results of HemiCAP resurfacing implant. Acta Orthop Traumatol Turc. 2012; 46:17-21.

3. Brodsky JW, Passmore RN, Pollo FE, Shabat S. Functional outcome of arthrodesis of the first metatarsophalangeal joint using parallel screw fixation. Foot Ankle Int. 2005;26(2):140-146.

4. Carpenter B, Smith J, Motley T, Garrett A. Surgical treatment of hallux rigidus using a metatarsal head resurfacing implant: mid-term follow-up. J Foot Ankle Surg. 2010;49(4):321-325.

5. Cook E, Cook J, Rosenblum B, Landsman A, Giurini J, Basile P. Metaanalysis of first metatarsophalangeal joint implant arthroplasty. J Foot Ankle Surg. 2009;48(2):180-190.

6. Coughlin MJ, Abdo RV. Arthrodesis of the first metatarsophalangeal joint with Vitallium plate fixation. Foot Ankle Int. 1994;15(1): 18-28.

7. Coughlin MJ, Shurnas PS. Hallux rigidus: demographics, etiology, and radiographic assessment. Foot Ankle Int. 2003;24(10):731-743.

8. Gibson JN, Thomson CE. Arthrodesis or total replacement arthroplasty for hallux rigidus: a randomized controlled trial. Foot Ankle Int. 2005;26(9):680-690.

9. Gordon M, Bullough PG. Synovial and osseous inflammation in failed silicone-rubber prostheses. A report of six cases. J Bone Joint Surg. 1982;64:574-580.

10. Gould N. Hallux rigidus: cheilotomy or implant? Foot Ankle. 1981;1(6): 315-320.

11. Hamilton WG, O’Malley MJ, Thompson FM, Kovatis PE. Capsular interposition arthroplasty for severe hallux rigidus. Foot Ankle Int. 1997;18: $68-70$.

12. Hasselman C, Shields N. Resurfacing of the first metatarsal head in the treatment of hallux rigidus. Tech Foot Ankle Surg. 2008;7:31-40.

13. Hattrup SJ, Johnson KA. Subjective results of hallux rigidus following treatment with cheilectomy. Clin Orthop Relat Res. 1988;226: 182-191.

14. Ibrahim T, Beiri A, Azzabi M, Best AJ, Taylor GJ, Menon DK. Reliability and validity of the subjective component of the American Orthopaedic Foot and Ankle Society clinical rating scales. J Foot Ankle Surg. 2007;46(2):65-74.

15. Keiserman LS, Sammarco VJ, Sammarco GJ. Surgical treatment of the hallux rigidus. Foot Ankle Clin. 2005;10(1):75-96.

16. Kennedy JG, Chow FY, Dines J, Gardner M, Bohne WH. Outcomes after interposition arthroplasty for treatment of hallux rigidus. Clin Orthop Relat Res. 2006;445:210-215.

17. Kilmartin TE. Phalangeal osteotomy versus first metatarsal decompression osteotomy for the surgical treatment of hallux rigidus: a prospective study of age-matched and condition-matched patients. J Foot Ankle Surg. 2005;44(1):2-12.

18. Kitaoka HB, Alexander IJ, Adelaar RS, Nunley JA, Myerson MS, Sanders M. Clinical rating systems for the ankle-hindfoot, midfoot, hallux, and lesser toes. Foot Ankle Int. 1994;15(7):349-353.

19. Sammarco VJ, Nichols R. Orthotic management for disorders of the hallux. Foot Ankle Clin. 2005;10(1):191-209.

20. Sorbie C, Saunders GA. Hemiarthroplasty in the treatment of hallux rigidus. Foot Ankle Int. 2008;29(3):273-281.

21. Townley CO, Taranow WS. A metallic hemiarthroplasty resurfacing prosthesis for the hallux metatarsophalangeal joint. Foot Ankle Int. 1994; 15(11):575-580.

22. Koenig RD, Horwitz LR. The Biomet Total Toe system utilizing the Koenig score: a five-year review. J Foot Ankle Surg. 1996;35(1): 23-26.

23. Konkel KF, Menger AG, Retzlaff SA. Mid-term results of futura hemigreat toe implants. Foot Ankle Int. 2008;29(8):831-837.
24. Konkel KF, Menger AG, Retzlaff SA. Results of metallic hemi-great toe implant for grade III and early grade IV hallux rigidus. Foot Ankle Int. 2009;30(7):653-660.

25. Pulavarti RS, McVie JL, Tullochn CJ. First metatarsophalangeal joint replacement using the bio-action great toe implant: intermediate results. Foot Ankle Int. 2005;26(12):1033-1037.

26. Swanson AB, Lumsden RM, Swanson GD. Silicone implant arthroplasty of the great toe: a review of single stem and flexible hinge implants. Clin Orthop. 1979;142:30-43.

27. Rahman H, Fagg PS. Silicone granulomatous reactions after first metatarsophalangeal hemiarthroplasty. J Bone Joint Surg Br. 1993;75(4): 637-639.

28. Shereff MJ, Jahss MH. Complications of silastic implant arthroplasty in the hallux. Foot Ankle. 1980;1(2):95-101.

29. Bryant A, Tinley P, Singer K. A comparison of radiographic measurements in normal, hallux valgus, and hallux limitus feet. J Foot Ankle Surg. 2000;39:39-43.

30. Smith RW, Joanis TL, Maxwell PD. Great toe metatarsophalangeal joint arthrodesis: a user friendly technique. Foot Ankle. 1992;13:367-377.

31. Raikin SM, Ahmad J, Pour AE, Abidi N. Comparison of arthrodesis and metallic hemiarthroplasty of the hallux metatarsophalangeal joint. J Bone Joint Surg Am. 2007;89(9):1979-1985.

32. Coughlin MJ, Shurnas PS. Soft-tissue arthroplasty for hallux rigidus. Foot Ankle Int. 2003;24(9):661-672.

33. Horton GA, Park YW, Myerson MS. Role of metatarsus primus elevatus in the pathogenesis of hallux rigidus. Foot Ankle Int. 1999;20(12): $777-780$.

34. Fitzgerald JA, Wilkinson JM. Arthrodesis of the metatarsophalangeal joint of the great toe. Clin Orthop Relat Res. 1981;157:70-77.

35. Mann RA, Oates JC. Arthrodesis of the first metatarsophalangeal joint. Foot Ankle. 1980;1(3):159-166.

36. Brage ME, Ball ST. Surgical options for salvage of end-stage hallux rigidus. Foot Ankle Clin. 2002;7(1):49-73.

37. Coughlin MJ. Arthrodesis of the first metatarsophalangeal joint. Orthop Rev. 1990;19(2):177-186.

38. Fitzgerald JA. A review of long-term results of arthrodesis of the first metatarsophalangeal joint. J Bone Joint Surg Am. 1969;51:488-493.

39. Henry AP, Waugh W, Wood H. The use of footprints in assessing the results of operations for hallux valgus: a comparison of Keller's operation and arthrodesis. J Bone Joint Surg Am. 1975;57:478-481.

40. Ess $P$, Hämäläinen M, Leppilahti J. Non-constrained titanium-polyethylene total endoprosthesis in the treatment of hallux rigidus. A prospective clinical 2-year follow-up study. Scand J Surg. 2002;91(2):202-207.

41. Fuhrmann RA, Wagner A, Anders JO. First metatarsophalangeal joint replacement: the method of choice for end-stage hallux rigidus? Foot Ankle Clin. 2003;8(4):711-721.

42. Fuhrmann RA. MTP prosthesis (Reflexion ${ }^{\mathrm{TM}}$ ) for hallux rigidus. Tech Foot Ankle Surg. 2005;4:2-9.

43. Lange J, Merk H, Barz T, Walther C, Follak N. Titanium arthroplasty ToeFit-Plus for the hallux metatarsophalangeal joint. Z Orthop Unfall. 2008;146:609-615.

44. Daniilidis K, Martinelli N, Marinozzi A, et al. Recreational sport activity after total replacement of the first metatarsophalangeal joint: a prospective study. Int Orthop. 2010;34(7):973-979.

45. Barták V, Popelka S, Hromádka R, Pech J, Jahoda D, Sosna A. ToeFitPlus system for replacement of the first metatarsophalangeal joint. Acta Chir Orthop Traumatol Cech. 2010;77:222-227.

46. Erdil M, Bilsel K, Imren Y, et al. Metatarsal head resurfacing hemiarthroplasty in the treatment of advanced stage hallux rigidus: outcomes in the short-term. Acta Orthop Traumatol Turc. 2012;46(4):281-285.

47. Meriç G, Erduran M, Atik A, Köse Ö, Ulusal AE, Akseki D. Short-term clinical outcomes after first metatarsal head resurfacing hemiarthroplasty for late stage hallux rigidus. J Foot Ankle Surg. 2015;54(2):173-178.

48. Kline AJ, Hasselman CT. Metatarsal head resurfacing for advanced hallux rigidus. Foot Ankle Int. 2013;34(5):716-725. 
Clinical Interventions in Aging

\section{Publish your work in this journal}

Clinical Interventions in Aging is an international, peer-reviewed journal focusing on evidence-based reports on the value or lack thereof of treatments intended to prevent or delay the onset of maladaptive correlates of aging in human beings. This journal is indexed on PubMed Central, MedLine,

CAS, Scopus and the Elsevier Bibliographic databases. The manuscript management system is completely online and includes a very quick and fair peer-review system, which is all easy to use. Visit http://www.dovepress. $\mathrm{com} /$ testimonials.php to read real quotes from published authors.

Submit your manuscript here: http://www.dovepress.com/clinical-interventions-in-aging-journal 